\title{
Treating a Pandemic Respiratory Disease with a Mutagen is a Doomsday Scenario
}

Leo Goldstein ${ }^{1}$

${ }^{1}$ Affiliation not available

January 21, 2022

Hosted file

Molnupiravir-Doomsday-AA.pdf available at https://authorea.com/users/449284/articles/547841-

treating-a-pandemic-respiratory-disease-with-a-mutagen-is-a-doomsday-scenario 